\title{
Pendidikan Kesehatan Melalui Media Booklet dan Audio Visual Untuk Meningkatkan Pengetahuan Tentang Konsumsi Buah dan Sayur
}

\author{
Tantiana Isnaningsih ${ }^{1 *}$ \\ 1. Program Studi Kesehatan Masyarakat, Sekolah Tinggi Ilmu Kesehatan Suryaglobal Yogyakarta \\ *email: tianingsih01@gmail.com
}

\begin{abstract}
Abstrak
Tujuan penelitian ini adalah untuk mengetaui pengaruh pendidikan kesehatan menggunakan media booklet dan audio visual terhadap pengetahuan anak tentang konsumsi buah dan sayur di Madrasah Ibtida'iyah Negeri1 Bantul. Daerah Istimewa Yogyakarta.

Jenis penelitian yang digunakan adalah penelitian Quasi Eksperiment, yaitu penelitian dengan melakukan . (perlakuan) pada subjek penelitian untuk mengetahui hasil perubahannya setelah diperlakukan oleh. tersebut. Penelitian ini bisa dilakukan tanpa atau dengan . pembanding (control group)

Populasi adalah seluruh objek penelitian atau objek yang diteliti. Populasi pada penelitian ini adalah kelas 5 A dan 5B di Madrasah Ibtida'iyah Negeril Bantul berjumlah 55 Siswa. Sampel diambil dengan cara Simple Random Sampling, Sampel yang digunakan adalah kelas 5 A dan 5B yang berjumlah 40 siswa.

Hasil perhitungan sebelum dan sesudah pendidikan kesehatan untuk kelompok intervensi menunjukkan adanya perubahan pengetahuan yaitu sebagian besar mendapat kategori "tidak baik" sebanyak 7 orang ( 35\%) Meningkat sesudah diberikan pendidikan kesehatan dengan kategori "baik" sebanyak 13 orang (65\%)
\end{abstract}

Kata Kunci: Audio Visual, Buah-Sayur, Media Booklet, Pendidikan Kesehatan, Pengetahuan.

\section{PENDAHULUAN}

Gizi seimbang merupakan susunan pangan sehari yang mengandung berbagai zat gizi dengan jenis dan jumlah yang sesuai dengan kebutuhan tubuh (Balitbangkes RI, 2014). Salah satu pesan gizi seimbang yaitu memperbanyak konsumsi sayur dan buah sebanyak 300-400 gram per orang per hari (Kemenkes RI, 2014). Sebagian besar masyarakat Indonesia masih kurang mengonsumsi sayur dan buah pada anak sekolah (Dhian, 2009).

Survey World Health Organization (WHO) masyarakat Indonesia terutama balita dan anak usia sekolah dianjurkan untuk mengkonsumsi sayuran dan buah-buahan 300-400 gram untuk setiap orang orang per hari bagi remaja dan orang dewasa sebanyak 400-600 gram untuk setiap orang per hari (Kemenkes, 2017).

Tingkat konsumsi sayuran masyarakat dunia secara berjenjang adalah Cina (270 kilogram per kapita per tahun), Singapura (120 kilogram per kapita per tahun), Myanmar (80 kilogram per kapita per tahun), Vietnam (75 kilogram per kapita per tahun), Filipina (55 kilogram per kapita per tahun), India (50 kilogram per kapita per tahun), Malaysia (49 kilogram per kapitaper tahun), Indonesia (35 kilogram per kapita per tahun), dan Thailand (30 kilogram per kapita per tahun) (Anonim \& Hariani, 2010). 
Buah dan sayur merupakan unsur yang penting bagi makanan yang sehat. Manfaat konsumsi buah dan sayur setiap hari untuk kesehatan badan mengingat tingginya kandungan beragam vitaMadrasah Ibtida'iyah Negeridan Madrasah Ibtida'iyah Negerieral serta serat pada buah dan sayur. Jika dikonsumsi dengan porsi yang dianjurkan, konsumsi buah dan sayur dapat mengurangi resiko defisiensi gizi mikro dan serangan penyakit tidak menular. Kurangnya konsumsi buah dan sayur merupakan risiko ke-10 tertinggi dari angka kematian di dunia (Data BPS,Susenas Maret 2012-2016).

Rendahnya konsumsi sayuran pada anak dipengaruhi oleh beberapa faktor, yaitu faktor pengetahuan, sikap, ketersediaan sayur, pendidikan, jenis kelaMadrasah Ibtida'iyah Negeri, kesukaan, keyakinan diri, kebiasaan orang tua, dukungan orang tua dan pengaruh teman sebaya (Fibrihirzani, 2012).

Menurut hasil Riset Kesehatan Daerah (RISKESDA) pada tahun 2007-2013 menunjukkan informasi frekuensi dan proporsi asupan sayur dan buah dikumpulkan dengan menghitung jumlah hari konsumsi dalam seMadrasah Ibtida'iyah Negeriggu dan jumlah porsi rata-rata dalam sehari. Penduduk dikategorikan " cukup" mengonsumsi sayur dan atau buah apabila makan sayur dan atau buah Madrasah Ibtida'iyah Negeriimal 5 porsi per hari selama 7 hari dalam seMadrasah Ibtida'iyah Negeriggu. Dikategorikan "kurang" apabila konsumsi sayur dan buah dan atau buah kurang dari ketentuan diatas. Riskesdas menunjukkan hal yang sama sehingga dapat dilakukan analisis kecenderungan proporsi umur $\geq 10$ tahun yang mengonsumsi sayur dan buah.

Berdasarkan data Dinas Kesehatan Bagian Program dan Bagian Promosi Kesehatan merekomendasikan Puskesmas. untuk dijadikan sasaran tempat penelitian. Dengan pertimbangan Puskesmas. untuk hasil penjaringan status gizi di dapatkan hasil 71,63 hasil normal, 9,26 hasil gemuk, 19,11 kurus, 0,00 kurus sekali, dan 0,00 obesitas. Dan catatan Puskesmas. bukan kategori Puskesmas yang mendapatkan hasil penjaringan status gizi paling rendah.

Dari hasil studi pendahuluan di Puskesmas. dengan bagian gizi dan bagian promosi kesehatan untuk pelaksanaan pendidikan atau promosi kesehatan mereka tergantung pada program kerja yang telah disusun oleh puskesmas. Bisa jadi pendidikan kesehatan dilaksanakan satu bulan sekali, satu tahun sekali atau bahkan diMadrasah Ibtida'iyah Negerita tolong oleh pihak sekolah setempat untuk mengadakan penyuluhan. Untuk pendidikan kesehatan puskesmas telah melaksanakan GERMAS (Gerakan Masyarakat Hidup Sehat) dan PHBS (Perilaku Hidup Bersih Dan Sehat). Namun untuk pendidikan kesehatan khususnya tentang konsumsi sayur dan buah puskesmas belum menjadwalkannya. Dari 23 SD/MI dibawah wilayah kerja Puskesmas . Madrasah Ibtida'iyah Negeri1 Bantul belum dilakukan kegiatan pendidikan kesehatan khususnya konsumsi buah dan sayur. Berdasarkan wawancara dengan staff bagian promkes menyatakan sekarang gencar-gencarnya untuk mengkampanyekan pentingnya konsumsi buah dan sayur.

Tujuan penelitian ini adalah untuk mengetaui pengaruh pendidikan kesehatan menggunakan media booklet dan audio visual terhadap pengetahuan anak tentang konsumsi buah dan sayur di Madrasah Ibtida'iyah Negeril Bantul. Daerah Istimewa Yogyakarta. 


\section{Metode}

Jenis penelitian yang digunakan adalah penelitian Quasi Eksperiment, yaitu penelitian dengan melakukan. (perlakuan) pada subjek penelitian untuk mengetahui hasil perubahannya setelah diperlakukan oleh. tersebut. Penelitian ini bisa dilakukan tanpa atau dengan. pembanding (control group) (Notoatmodjo, 2014). Dengan bentuk rancanganNon Equivalent Control Group sebagai berikut:

Populasi adalah seluruh objek penelitian atau objek yang diteliti (Notoatmodjo,2012). Populasi pada penelitian ini adalah kelas 5 A dan 5B di Madrasah Ibtida'iyah Negeril Bantul berjumlah 55 Siswa. Sampel diambil dengan cara Simple Random Sampling, Sampel yang digunakan adalah kelas 5 A dan 5B yang berjumlah 40 siswa.

Hasil analisis instrument setiap item untuk semua variabel penelitian menggunakan pearson product moment dengan cara membandingkan hasil $r$ hitung $n=30(\mathrm{r}$ table $=0,361)$ dengan menggunakan program SPSS for windows. Berdasarkan hasil uji validitas untuk variabel pengetahuan, item pertanyaan dianggap valid jika $r$ hitung $>r$ tabel $(0,361)$.

Hasil uji reliabiltas untuk kuesioner variabel pengetahuan diperoleh nilai Cronbach's Alpha 0,674. Hal tersebut menunjukkan bahwa reliabilitas untuk variabel pada penelitian ini mempunyai Cronbach's Alpha lebih besar dari 0,60 sehingga instrument penelitian tersebut dinyatakan reliabel.

\section{Hasil}

Berdasarkan hasil rata-rata nilai pengetahuan diperoleh nilai sebagai berikut;

a. Perbedaan Pengetahuan Sebelum Dan Sesudah Mendapatkan Pendidikan Kesehatan

Tabel 1. Distribusi Frekuensi Perbedaan Pengetahuan Kelompok Intervensi Sebelum Dan Sesudah Mendapat Pendidikan Kesehatan

\begin{tabular}{ccc}
\hline & Hasil Pretest & Hasil Posttest \\
\hline Mean & 6,15 & 8,35 \\
\hline
\end{tabular}

Sumber: Data Primer

Berdasarkan tabel di atas diketahui bahwa pengetahuan siswa tentang konsumsi buah dan sayur di MIN 1 Bantul, sesudah diberikan pendidikan kesehatan mengalami peningkatan hasil yaitu mean pretest 6,15 meningkat menjadi 8,35 pada posttest.

Tabel 2. Distribusi Frekuensi Perbedaan Pengetahuan

\begin{tabular}{ccc}
\hline & Hasil Pretest & Hasil Posttest \\
\hline Mean & 5,90 & 7,65 \\
\hline
\end{tabular}

Sumber: Data Primer 
Berdasarkan tabel di atas diketahui bahwa pengetahuan siswa tentang konsumsi buah dan sayur di MIN 1 Bantul, sesudah diberikan pendidikan kesehatan mengalami peningkatan hasil yaitu mean pretest 5,90 meningkat menjadi 7,65 pada posttest.

b. Analisis Uji Eksperimen

1. Uji Prasyarat Analisis

Tabel 3. Hasil Uji Normalitas Data Kelompok Intervensi Menggunakan Uji Sample Kolmogorov-Smirnor Test

\begin{tabular}{lcc}
\hline & $\begin{array}{l}\text { Sebelum } \\
\text { Pendidikan } \\
\text { Kesehatan }\end{array}$ & $\begin{array}{l}\text { Sesudah Pendidikan } \\
\text { Kesehatan }\end{array}$ \\
\hline $\begin{array}{l}\text { Kolmogorov- } \\
\text { Smirnor Test }\end{array}$ & 0,314 & 0,724 \\
\hline
\end{tabular}

Sumber: Data Primer

Berdasarkan tabel di atas hasil dari uji normalitas data kelompok intervensi menggunakan uji sampel Kolmogorov-Sminornov Test diketahui bahwa data menunjukkan berdistribusi normal pada hasil pretest yaitu 0,314 dan pada hasil posttest yaitu 0,724 dengan ukuran normal jika signifikansi di atas 0,05

Tabel 4. Hasil Uji Normalitas Data Kelompok Kontrol Menggunakan Uji Sample Kolmogorov-Smirnor Test

\begin{tabular}{lcc}
\hline & $\begin{array}{l}\text { Sebelum } \\
\text { Pendidikan } \\
\text { Kesehatan }\end{array}$ & $\begin{array}{l}\text { Sesudah Pendidikan } \\
\text { Kesehatan }\end{array}$ \\
\hline $\begin{array}{l}\text { Kolmogorov- } \\
\text { Smirnor Test }\end{array}$ & 0,231 & 0,818 \\
\hline \multicolumn{2}{l}{ Sumber: Data Primer } &
\end{tabular}

Berdasarkan tabel di atas hasil dari uji normalitas data kelompok intervensi menggunakan uji Sample Kolmogorov-Sminornov Test diketahui bahwa data menunjukkan berdistribusi normal pada hasil pretest yaitu 0,231 dan pada hasil posttest yaitu 0,818 dengan ukuran normal antara ukuran normal jika signifikansi di atas 0,05 .

2. Uji Hipotesis

Tabel 5. Perbedaan Pengetahuan Kesehatan Tentang Konsumsi Buah Dan Sayur Sebelum Dan Sesudah Pendidikan Kesehatan Kelompok Intervensi Dengan Menggunakan T Paired Test

\begin{tabular}{lccc}
\hline & T & Df & Sig. (2-tailed) \\
\hline $\begin{array}{l}\text { Sebelum pendidikan } \\
\text { kesehatan - Sesudah }\end{array}$ & -4.305 & 19 & 0,000 \\
pendidikan kesehatan & & & \\
\hline \multicolumn{2}{c}{ Sumber: Data Primer }
\end{tabular}


Berdasarkan tabel di atas dapat diketahui bahwa nilai Signifikan $=0,000$. Karena nilai signikan $(0,000)<0,05$ maka Ho ditolak dan Ha diterima yaitu ada perbedaan pengetahuan konsumsi buah dan sayur sebelum dan sesudah diberikan pendidikan kesehatan.

Tabel 6. Perbedaan Pengetahuan Kesehatan Tentang Konsumsi Buah Dan Sayur kelompok Konrol Dengan Menggunakan T Paired Test

\begin{tabular}{|c|c|c|c|}
\hline & $\mathrm{T}$ & Df & Sig. (2-tailed) \\
\hline $\begin{array}{l}\text { Sebelum } \\
\text { pendidikan } \\
\text { kesehatan } \\
\text { Sesudah } \\
\text { pendidikan } \\
\text { kesehatan }\end{array}$ & -3.114 & 19 & 0,005 \\
\hline
\end{tabular}

Sumber: Data Primer

Berdasarkan tabel di atas dapat diketahui bahwa nilai Signifikan $=0,005$. Karena nilai signikan $(0,000)<0,05$ maka Ho ditolak dan Ha diterima yaitu ada perbedaan pengetahuan konsumsi buah dan sayur sebelum dan sesudah diberikan pendidikan kesehatan.

\section{Pembahasan}

\section{Pengetahuan Siswa MIN 1 Bantul ,Sebelum Pendidikan Kesehatan}

Penelitian tentang pengaruh pendidikan kesehatan menggunakan media booklet dan audio visual terhadap pengetahuan anak tentang konsumsi buah dan sayur ini dilaksanakan di MIN 1 Bantul, DIY dengan jumlah responden sebanyak 40 siswa. Penelitian ini dilaksanakan pada hari Kamis 24 Januari 2019.

Berdasarkan hasil penelitian terhadap 40 siswa yang meliputi kelompok intervensi atau kelompok perlakuan dengan kelompok kontrol didapati hasil bahwa sebelum mendapatkan pendidikan kesehatan menggunakan media booklet dan audio visual tentang konsumsi buah dan sayur sebagian besar mendapati kategoritidak baik yaitu 7 orang $(35 \%)$ dan kategori baik 13 orang (65\%) untuk kelompok intervensi. Dan kategori tidak baik 7 orang (35\%) dan kategori tidak baik 13 orang $(65 \%)$ untuk kelompok kontrol.

Responden yang berpengetahuan dengan kategori tidak baik sebagian besar belum mengetahui secara jelas tentang pentingnya konsumsi buah dan sayur.

Masa anak adalah masa keemasan atau sering disebut masa Golden Age. Biasanya ditandai oleh perubahan cepat dalam perkembangan fisik, kognitif, sosial dan emosional. Masa anakanak adalah masa seluruh aspek perkembangan kecerdasan spiritual mengalami perkembangan yang sangat luar biasa(Nurrsalam, 2013). Anak adalah sosok individu yang sedang menjalani suatu proses perkembangan dengan pesat dan fundamental bagi kehidupan selanjutnya (Sujiono, 2009).

Menurut (Wahit, 2009) anak usia sekolah atau anak yang sudah sekolah akan menjadi pengalaman inti anak. Periode ini anak-anak dianggap mulai bertanggungjawab 
atasperilakunya sendiri dalam hubungan dengan orang tua mereka, teman sebaya, dan orang lain. Usia sekolah merupakan masa anak memperolah dasar-dasar pengetahuan untuk keberhasilan penyesuaian diri pada kehidupan dewasa dan memperolah keterampilan tertentu.

Pengetahuan yang baik tentang konsumsi buah dan sayur adalah sangat penting untuk diketahui terutama oleh anak usia sekolah. Pentingnya pengetahuan mengenai konsumsi buah dan sayur juga dikuatkan dengan tingginya kasus kematian akibat tidak suka mengkonsumsi buah dan sayur dan kekurangan buah dan sayur.

Hasil penelitian pengetahuan santriwati tentang pengetahuan konsumsi buah dan sayur juga didukung oleh hasil penelitian Rahmad dkk (2017) dengan judul "Pemanfaatan media flipchart dalam meningkatkan pengetahuan ibu tentang konsumsi sayur dan buah" dengan hasil penelitian pretest sebelum diberikan penyuluhan yaitu $(7,5)$ untuk kelompok intervensi. Dan $(7,8)$ untuk kelompok kontrol atau kelompok yang tidak diberikan penyuluhan tanpa media, yang berarti bahwa pengetahuan masyarakat sebelum diberikan pendidikan sebagian besar dalam kategori rendah.

\section{Pengetahuan Siswa MIN 1 Bantul Sesudah Pendidikan Kesehatan.}

Berdasarkan hasil penelitian sesudah diberikan pendidikan kesehatan menggunakan media booklet dan audio visual terhadap pengetahuan buah dan sayur anak kepada 40 responden yang meliputi kelompok intervensi dan kelompok kontrol dapat dilihat bahwa pengetahuan responden sebagian besar meningkat yaitu mendapat kategori "tidak baik" sebanyak 6 orang (30\%) dan kategori "baik" sebanyak 14 orang (70\%) untuk ktlompok kelompok intervensi. Kategori "tidak baik" sebanyak 9 orang (45\%) dam kategori "baik" sebanyak 11 orang (55\%) untuk kelompok kontrol. Dari peningkatan hasil pengetahuan ini merupakan pengaruh dari diberikannya pendidikan kesehatan.

Pendidikan kesehatan pada hakikatnya adalah suatu kegiatan atau usaha untuk menyampaikan pesan kesehatan kepada masyarakat, kelompok, dan individu. Dengan harapan bahwa dengan adanya pesan tersebut, masyarakat, kelompok, atau individu dapat memperoleh pengetahuan tentang kesehatan yang lebih baik. Akhirnya pengetahuan tersebut diharapkan dapat berpengaruh terhadap perilakunya. Dengan kata lain, dengan adanya pendidikan tersebut dapat membawa akibat terhadap perubahan perilaku sasaran (Notoatmodjo, 2011).

Penyuluhan kesehatan merupakan kegiatan pendidikan kesehatan yang dilakukan dengan menyebarkan pesan, menanamkan keyakinan sehingga masyarakat tidak saja sadar, tahu, dan mengerti, tetapi juga mau dan dapat melakukan anjuran yang berhubungan dengan kesehatan. Petugas penyuluh kesehatan harus menguasai ilmu komunikasi dan menguasai pemahaman yang lengkap tentang pesan yang akan disampaikan. Penyuluhan kesehatan dalam promosi kesehatan diperlukan sebagai upaya meningkatkan pengetahuan dan kesadaran, dismping pengetahuan dan sikap perbuatan. Oleh karena itu, tentu diperlukan upaya penyediaan dan penyampaian informasi, yangmerupakanbidang garapan penyuluhan kesehatan. Makna asli penyuluhan adalah pemberian penerangan dan informasi (Heri, 2018).

Pada penelitian ini peneliti untuk sampel responden pada kisaran usia 10-12 tahun dengan alasan usia ini tergolong usia anak-anak dan tepat untuk diberikan pendidikan kesehatan. Melihat dimana daya pikir dalam menerima pengetahuan tumbuh pesat diusia pra-remaja. 
Hasil penelitian pengetahuan santriwati tentang pengetahuan konsumsi buah dan sayur juga didukung oleh hasil penelitian Rahmad dkk (2017) dengan judul "Pemanfaatan media flipchart dalam meningkatkan pengetahuan ibu tentang konsumsi sayur dan buah" dengan hasil penelitian posttest setelah diberikan penyuluhan menggunakan mediaflipchartyaitu $(10,3)$ dengan deviasi 1,6

3. Pengaruh Pendidikan Kesehatan Menggunakan Media Booklet Dan Audio Visual Terhadap Pengetahuan Tentang Konsumsi Buah Dan Sayur Di MIN 1 Bantul ,Daerah Istimewa Yogyakarta

Pengaruh pendidikan kesehatan menggunakan media booklet dan audio visual terhadap pengetahuan anak tentang konsumsi buah dan sayur Di MIN 1 Bantul ,Daerah Istimewa Yogyakarta. Hasil analisis menggunakan uji $t$ paired test menunjukkan pengaruh pendidikan kesehatan menggunakan media booklet dan audio visual terhadap pengetahuan anak tentang konsumsi buah dan sayur Di MIN 1 Bantul ,Daerah Istimewa Yogyakarta, dan terdapat perbedaan yang signifikan antara sebelum dan sesudah diberikan pendidikan kesehatan. Hal ini dikarenakan nilai $\mathrm{P}=0,005<\alpha=0,05$ dengan artian Ha diterima untuk kelompok intervensi. Dan $0,000<\alpha=0,05$ dengan artian Ha diterima untuk kelompok control.

Hasil distribusi frekuensi sebelum dan sesudah pendidikan kesehatan juga menunjukkan adanya perubahan pengetahuan yaitu sebelum diberi pendidikan kesehatan SADARI sebagian besar memiliki mendapat kategori "tidak baik" sebanyak 7 orang $(35 \%)$ untuk kelompok inyervensi dan kategori "tidak baik" 9 orang (45\%) untuk kelompok control. Meningkat sesudah diberikan pendidikan kesehatan dengan kategori "baik" sebanyak 14 orang (65\%) unruk kelompok intervensi dan kategori "baik" 11 orang $(55 \%)$ untuk kelompok kontrol. Pemberia pendidikan kesehatan akan semakin meningkatakan pengetahuan anak tentang konsumsi buah dan sayur.

Hasil penelitian pengetahuan santriwati tentang pengetahuan konsumsi buah dan sayur juga didukung oleh hasil penelitian Rahmad dkk (2017) dengan judul "Pemanfaatan media flipchart dalam meningkatkan pengetahuan ibu tentang konsumsi sayur dan buah" dengan penelitian quasy eksperimandengan design dengan non equivalent control group menunjukkan bahwa ada pengaruh pendidikan kesehatan menggunakan media booklet dan audio visual terhadap pengetahuan anak tentang konsumsi buah dan sayur.

Pendidikan kesehatan adalah suatu penerapan konsep pendidikan dalam bidang kesehatan. Oleh sebab itu, konsep pendidikan kesehatan adalah konsep pendidikan yang diaplikasikan dalam bidang kesehatan. Bertitik tolak dari konsep pendidikan tersebut, maka konsep pendidikan kesehatan itu juga proses belajar pada individu, kelompok atau masyarakat dari tidak tahu tentang nilai-nilai kesehatan menjadi tahu, dari tidak mampu mengatasi masalahmasalah kesehatannya sendiri menjadi mampu, dan lain sebagainya. (Notoatmodjo, 2011). Sehingga, penelitian ini juga dikategorikan berhasil meningkatkan pengetahuan santri tentang pengetahuan konsumsi buah dan sayur. Penyuluhan menggunakan media maupun tanpa media sangat bermanfaat dalam meningkatkan pengetahuan. 


\section{Kesimpulan}

Pendidikan kesehatan mengggunakan media booklet dan audio visual terhadap pengetahuan anak tentang konsusmi buah dan sayur dapat ditarik kesimpulan sebagai berikut :

1. Hasil perhitungan sebelum dan sesudah pendidikan kesehatan untuk kelompok intervensi menunjukkan adanya perubahan pengetahuan yaitu sebagian besar mendapat kategori "tidak baik" sebanyak 7 orang ( 35\%) Meningkat sesudah diberikan pendidikan kesehatan dengan kategori "baik" sebanyak 13 orang (65\%).

2. Ada pengaruh pendidikan kesehatan menggunakan media booklet dan audio visual terhadap pengetahuan anak tentang konsumsi buah pada siswa dengan nilai Signifikan= 0,005 untuk kelompok intervensi dan 0,000 untuk kelompok kontrol. Karena nilai signikan $(0,005)<0,05$ maka Ho ditolak dan Ha diterima untuk kelompok intervensi. Dan $(0,000)$ $<0,05)$ untuk kelompok kontrol yaitu ada perbedaan pengetahuan di kedua kelompok

\section{Referensi}

Anonim dan Hariani.( 2013) Faktor-Faktor Yang Berhubungan Dengan Konsumsi Sayur Pada Anak SD Negeri 05 Simpang Tiga Kecamatan Luhuk Nan Duo Kabupaten Pasaman Barat Tahun. Jurnal Pendidikan Kesehatan Journal of Nutrition and Food Vol 10, No 1 (2015)

Badan Pusat Statistik (2012-2017) Data Susenas

Badan Pusat Statistik(2012-2017) Kab Bantul. Data Susenas

Dharma. Kelana. 2011. Metodologi Penelitian Keperawatan. CV Trans Media: Jakarta Timur

Dinkes. (2017) Data Profil Gizi. Bantul:Dinkes.

Dinkes. 2018. Profil Kesehatan Kabupaten Bantul. Bantul:Dinkes.

Kementerian Kesehatan RI. (2013) Rapor Kesehatanku Untuk Peserta Didik Tingkat SD/MI. Jakarta: Direktorat Bina Kesehatan Anak; Direktorat Jendral Bina Gizi dan KIA.

Kementerian Kesehatan RI. (2017) Tingkatkan Konsumsi Sayur dan Buah Nusantara Menuju Masyarakat Hidup Sehat. Article.

Notoatmodjo, S. (2011) Perilaku dan Pendidikan Kesehatan. Rineka Cipta. Jakarta.

Notoatmodjo, S. (2012) Metodologi Penelitian Kesehatan. Rineka Cipta. Jakarta.

Notoatmodjo, S. (2012) Promosi Kesehatan \& Ilmu Perilaku. Jakarta: Rineka Cipta.

Notoatmodjo, S. (2014) Metodologi Penelitian Kesehatan. Rineka Cipta. Jakarta.

Nursalam. (2013) Metodologi Penelitian Ilmu Keperawatan Pendekatan Praktis Edisi 3. Salemba Medika . Jakarta Selatan 
Sunyoto, danang. (2012) Statistik Kesehatan Analisis Data dengan Perhitungan Manual dan Program SPSS .. Bandung Medical Book

Wahit. Iqbal. Mubarak dkk. Promosi Kesehatan: Sebuah Pengantar Proses Belajar Mengajar dalam Pendidikan. Graha Ilmu: Yogyakarta 